EESTI NSV TEADUSTE AKADEEMIA TOIMETISED. XIV KÖIDE

FOOSIKA-MATEMAATIKA. JA TEHNIKATEADUSTE SEERIA, 1965, NR. 1

ИЗВЕСТИЯ АКАДЕМИИ НАУК ЭСТОНСКОИ ССР. ТОМ ХІV

СЕРИЯ ФИЗИКО-МАТЕМАТИЧЕСКИХ И ТЕХНИЧЕСКИХ НАУК. 1965, № 1

\author{
С. САЛУСТЕ, И. КЛЕСМЕНТ, О. ЭИЗЕН
}

\title{
СОСТАВ ФЕНОЛОВ ТУННЕЛЬНЫХ ПЕЧЕЙ
}

\section{Сообщение I}

Опубликованные до настоящего времени результаты исследования фенолов сланцевой смолы сводятся к определению группового состава фенолов и к идентификации ряда индивидуальных соединений с применением химических методов. Так, в сланцевой смоле обнаружены фенол, крезолы, этилфенолы, диметилфенолы, некоторые полиметил- и этилфенолы, нафтолы и отдельные двухосновные фенолы [1, 2]. Однако до сих пор отсутствуют количественные данные об индивидуальном составе фенолов сланцевой смолы.

Целью настоящей работы было наряду с идентифнкацией фенолов получение данных о содержанни отдельных индивидуальных фенолов в сланцевой смоле. В сообщении приводятся результаты исследования фенолов фракций бензина и легкой смолы туннельных печей, кипящих в пределах $192-290^{\circ} \mathrm{C}$. Так как полукоксование сланца в туннельной печи протекает при более низкой температуре $(480-5009)$, чем в других установках полукоксования, то следует предполагать, что структура фенолов смолы туннельной печи ближе к структуре исходного керогена.

В качестве исходной пробы для извлечения фенолов использовали смесь сырого бензина и легкой смолы туннельной печи № 3 Қивиыли, характеристика которых приводится в табл. 1.

Фенолы выделялись из смолы в виде фенолята путем повторной обработки одним и тем же количеством $10 \%$-ной $\mathrm{NaOH}$. Щелочь бралась с $20 \%$-ным избытком соответственно содержанию группы ОН в смоле. Нейтральное масло отделялось от фенолята троекратной экстракцией эфиром. Выход фенолов, полученных разложением фенолята серной кислотой, составлял $11,4 \%$ от дефенолируемой смолы. Выделенные сырые фенолы отгонялись от тяжеТаблица 1

Характеристика дефенолируемой смолы

\begin{tabular}{c|c|c|c}
\hline Показатели & Бензин & $\begin{array}{c}\text { Легкая } \\
\text { смола }\end{array}$ & Смесь \\
\hline Выход от исходной & & & \\
смолы, вес. \% & 9,2 & 24,0 & 33,2 \\
Удельный вес, $d_{4}^{20}$ & 0,773 & 0,882 & 0,843 \\
Фракционный состав: & & & \\
начало кипения, ${ }^{\circ} \mathrm{C}$ & 71 & 84 & 72 \\
выкипает до 200 & 87 & 34 & 38 \\
" " $250^{\circ}$ & 94 & 59 & 61 \\
конец кипения, ${ }^{\circ} \mathrm{C}$ & 98 & - & 81 \\
Выход дистиллята, & 292 & - & 340 \\
об. \% & 98 & 59 & 88 \\
Содержание фенолов, & & & \\
вес. \% & 3,0 & 14,5 & 11,4 \\
\end{tabular}

лого остатка в колбе Клайзена, выход дистиллята составлял $82,3 \%$. Затем дистиллят фенолов разгоняли в вакуумной колонке эффективностью 60 теоретических тарелок (остаточное давление $3-10$ мм рт. ст.) на 62 узкие фракции с пределами кипения 192-370 (в перерасчете на атмосферное давление). Суммарный выход этих фракций составляет 
$3,8 \%$ от исходной суммарной смолы. Ректификационная кривая и показатели, характеризующие полученные фракции, изображены на рис. 1. Для дальнейшего исследования использовали 20 фракций с пределами кипения $192-290^{\circ}$, составляющих $0,82 \%$ от исходной смолы.

Как известно, по своей структуре фенолы являются ароматическими соединениями с гидроксильной группой. Смесь их состоит из индивидуальных компонентов, количество которых по сравнению с ароматическими соединениями соответствующей структуры в несколько раз больше, так как гидроксильная группа может находиться в нескольких различных положениях относительно ядра. Физические свойства отдельных изомеров весьма близки, и поэтому определение их путем даже наиболее эффективного современного метода анализа, каковым является метод газо-жидкостной хроматографии, затруднено. Несколько более точные данные о составе фенолов можно получить путем использования двух неподвижных фаз, одна из которых полярна, другая - неполярна $\left[{ }^{3,4}\right]$. Препятствием является также отсутствие необходимых эталонов для идентификации компонентов. Это особенно ощутимо при анализе высокомолекулярных фенолов, к числу которых относятся и сланцевые фенолы.

В настоящей работе параллельно применялись два метода анализа:

1) прямое газохроматографирование;

2) микрореакторно-газохроматографическое дегидроксилирование фенолов.

Второй метод разработан в Институте химии АН ЭССР [5]. C его. помощью нельзя определить расположение гидроксильной группы, однако он дает возможность установить углеводородный скелет фенолов.

Прямое хроматографирование фенолов осуществлялось на хроматографе УХ-1. Наполнитель колонок состоял из апиезона L, $15 \%$ от хромосорба W. Газ-носитель - водород. Количество анализируемой пробы составляло $3-5$ ма. Фракции с пределами кипения $192-247^{\circ}$ анализировались на 6-метровой колонке при $170^{\circ}$, фракции с пределами кипения $247-290^{\circ}-$ на 6-метровой колонке при $200^{\circ}$.

При дегидроксилировании фенолов в микрореакторно-газохроматографической установке использовался катализатор палладий на силикагеле марки ШСК, 5\% от носителя, оказавшийся наиболее подходящим для гидрирования и дегидрирования из числа катализаторов, исследованных в настоящей работе.* В качестве микрореакторов были применены медные трубки с внутренним диаметром 4-8 мм, длиной 50 100 cм, вставленные для обогрева в трубчатую печь. Реакторы устанавливались в хроматографе УХ-1 на место 1-й колонки; выступающие из трубчатой печи концы реактора заполнялись стеклянной насадкой во избежание попадания катализатора в зону более низкой температуры $\left[{ }^{6,7]}\right.$. Количество катализатора составляло 2-20 мл. В реакторе поддерживалась температура $340^{\circ}$, так как при более низкой температуре происходит образование производного циклогексана, а при более высокой протекают реакции дезалкилирования.

При анализе более легких фракций проба (3--5 мح) вводилась непосредственно в поток водорода, с которым она проходила через микрореактор и попадала в газохроматографическую колонку, где разделялись продукты реакции - ароматические углеводороды, образовавшиеся при дегидроксилировании фенолов.

\footnotetext{
* Результаты этой части исследования будут опубликованы отдельно.
} 
В случае более тяжелых фракций наблюдалась адсорбция фенолов на катализаторе, в результате чего точность хроматографического разделения уменьшалась. Поэтому катализат этих фракций предварительно конденсировали в стеклянных $U$-образных приемниках, погруженных в твердую углекислоту. Работу с высококипящими фенолами проводили в двух вариантах:

1) с бо́льшим количеством катализатора $(20$ мл) и исходной пробы: (до 50 мг), с газохроматографическим исследованием конденсата на yX-1;

2) с меньшим количеством катализатора (2 мл) и пробы (3-5 мг), с исследованием конденсата на аргонном хроматографе «Пай» (с чувствительным $\beta$-ионизационным детектором).

При анализе ароматических углеводородов наполнитель газохроматографических колонок состоял из полигликоля 4000 в количестве $20 \%$ от силоцеля. Анализ на приборе УХ-1 проводился с 6-метровой колонкой при 150 и $180^{\circ}$ и на приборе «Пай» с 3-метровой колонкой при $150^{\circ}$.

Для идентификации фенолов использовались данные литературы об относительных временах удерживания [8] и сравнение с чистыми эталонными веществами; так же идентифицировались ароматические углеводороды [9].

Отравляющее действие на катализатор оказывали нафтолы и другие высококипящие фенолы, особенно при использовании больших количеств катализатора и пробы. Применение меньших количеств катализатора и пробы увеличивало время действия катализатора.

Так как при конденсировании часть конденсата пропадает из-за большой летучести более легких компонентов, то за основу количественных расчетов следует брать хроматограммы катализата, непосредственно направленного из микрореактора в хроматографическую колонку.

Хроматограммы некоторых фракций фенолов и их продуктов дегидроксилирования изображены на рис. 2,3 и 4.

Во фракциях с пределами кипения $192-247^{\circ}$ по пикам хроматограммы были идентифицированы все компоненты фенолов. Для большинства из них характерно хорошее качественное и количественное соответствие с продуктами дегидроксилирования.

Количество низкокипящих фенолов в исследованной области невелико. Значительно содержание фенолов с пропиловой группой, например, во фракции $238-244^{\circ}$ они составляли $20 \%$. Фенолов с разветвленной боковой (изопропиловой) группой очень мало. Отметим высокое содержание инданолов: во фракции $244-265^{\circ}$ они составляли до $40 \%$.

\section{Распространено мне-} ние, что малополярные стационарные фазы, к числу которых относится и апиезон, разделяют компоненты в соответствии с их температурами кипения. В действительности разделение в соответствии со значением температур кипения происходит только в том случае, когда соединения обладают одинаковой полярностью. 2-Алкилгруппа оказывает экранирующее дейст-

\begin{tabular}{|c|c|c|}
\hline Название фенола & $\begin{array}{c}\text { Температура } \\
\text { кипения, }{ }^{\circ} \mathrm{C} \\
{\left[{ }^{12}\right]}\end{array}$ & $\begin{array}{l}\text { Относительное } \\
\text { время удержи- } \\
\text { вания }(M \text {-кре- } \\
\text { зол }=1,00)\end{array}$ \\
\hline $\begin{array}{l}\text { Фенол } \\
o \text {-Крезол } \\
\text { M-Крезол } \\
n \text {-Крезол } \\
2,4 \text {-Диметилфенол } \\
2,5 \text {-Диметилфенол } \\
2,3 \text {-Диметилфенол } \\
3,5 \text {-Диметилфенол }\end{array}$ & $\begin{array}{l}182 \\
191 \\
202,8 \\
202,5 \\
211,5 \\
211,5 \\
218 \\
219,5\end{array}$ & $\left\{\begin{array}{l}0,56 \\
0,92 \\
1,00 \\
1,60 \\
1,93 \\
1,87\end{array}\right.$ \\
\hline
\end{tabular}


вне на группу $\mathrm{OH}$, уменьшая полярность таких фенолов, в связи с чем их относительные времена удерживания на неполярных фазах больше, чем это можно было бы предугадать по температуре кипения. Данные, характеризующие «ортоэффект», приведены в табл. 2 .

При хроматографировании фракций с узкими пределами кипения нз-за этого эффекта пики фенолов, замещенных в положении 2 , несколько задерживаются. На рис. 2 по расположению пиков $1,2,3$ и $6,8,9$ отчетливо видно влияние «ортоэффекта». Так как $м$ - и $n$-изомеры обладают одинаковой полярностью, то при хроматографировании они не разделяются.

Анализ фракций фенолов, кипяших при температуре выше $250^{\circ}$, усложняется отсутствием эталонов с пределами кипения $250-280^{\circ}$ (от инданолов до нафтолов), а также отсутствием данных об относительных временах удерживания фенолов этой области.

По данным прямого газохроматографического анализа, в этой области обнаружено значительное количество различных фенолов (до двадцати пиков на хроматограмме). При этом, судя по расположению пиков, состав даже весьма близких по температуре кипения фракций различен. Несмотря на это, состав продуктов дегидроксилирования оказался близким - присутствуют в основном семь компонентов. Повышение температуры кипения привело к изменению их количественного соэтношения, в то время как качественный состав оставался прежним. Однако из-за отсутствия эталонов идентификация этих ароматических углеводородов оказалась невозможной. Так как в низкокипящих фракциях содержится много 4- и 5-инданолов, можно допустить присутствие в этом пределе метилинданола и высших алкилинданолов.

Заслуживает внимания тот факт, что нафталин возникает уже при дегидроксилировании относительно низкокипящих фракций фенолов, в которых по данным прямого газохроматографического анализа $\alpha$ - и $\beta$-нафтолы не обнаружены. Так, при дегидроксилировании фракции $260-265^{\circ}$ образовалось до 3,3 , фракции $265-272^{\circ}-13,5$ и фракции $272-277^{\circ}-15,7 \%$ нафталина. В наших ранних работах установлено, что в указанных условиях дегидроксилирования не происходит дегидроциклизации боковых цепей алкнлбензолов [6]. Единственной возможностью для образования нафталина является присутствие фенолов типа тетралина, т. е. тетрагидронафтолов, соединений с более низкой температурой кипения, чем нафтолы. В условиях наших опытов тетралин дегидрируется в нафталин.

Во фракциях, кипящих выше $272^{\circ}$, присутствует большое количество $\alpha$ - и $\beta$-нафтола. Так например, из фракции $277-283^{\circ}$ образовалось $27,5 \%$ нафталина, из фракции $283-288^{\circ}-35,3$, из фракции $288-290^{\circ}-44 \%$. При дегидроксилировании последней фракции образовалось также значительное количество $\alpha$ - и $\beta$-метилнафталина. Так как температура кипения исходной фракции сравнительно низка, можно предполагать, что эти соединения образовались из соответствующей структуры тетралина.

Двухосновные фенолы также дегидроксилируются в данных условиях в ароматические углеводороды. Образующиеся углеводороды имеют относительно меньший молекулярный вес, чем соединения с той же температурой кипения, образовавшиеся из высших алкилфенолов, и благоларя этому можно определить их структуру и количество в продуктах дегидроксилирования.

В сланцевых фенолах, содержащих нейтральный кислород, установлено наличие оксикумарона [']. В условиях дегидроксилирования из оксикумарона образуется этилбензол. Так как в области, отвечающей 


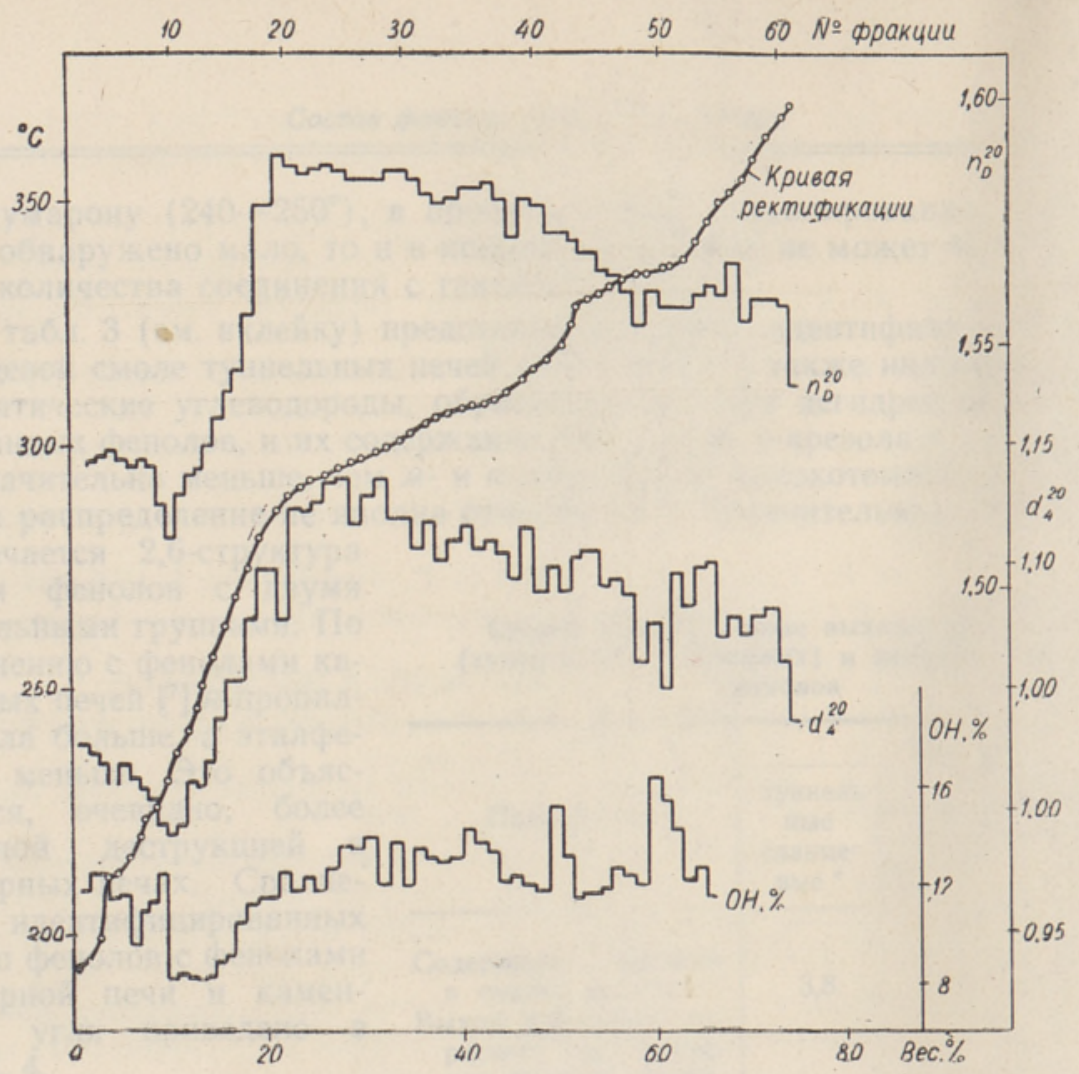

Рис. 1. Қривая ректификации фенолов и показатели, характеризующие полученные фракции.

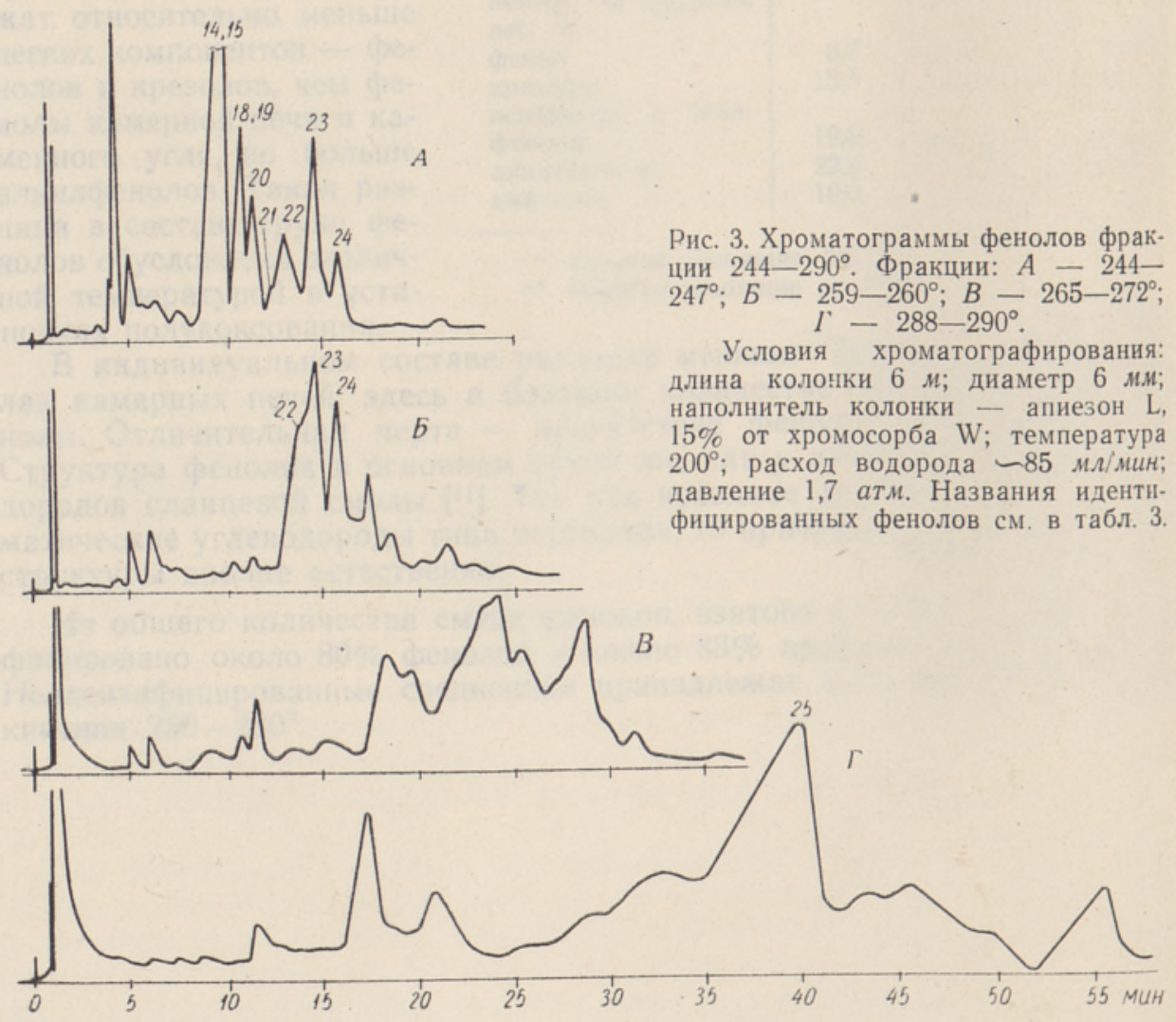

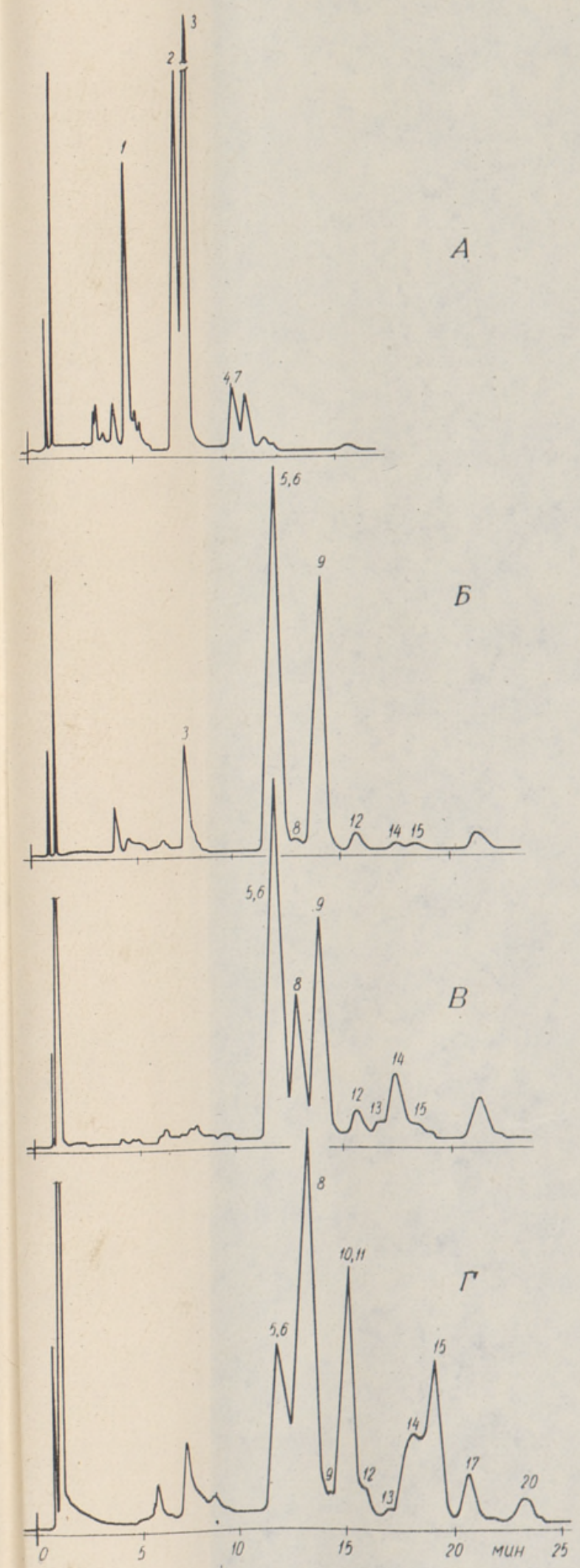


оксикумарону $\left(240-250^{\circ}\right)$, в продуктах дегидроксилирования этилбензола обнаружено мало, то и в исходном веществе не может быть заметного количества соединения с такой структурой.

В табл. 3 (см. вклейку) представлены фенолы, идентифицированные в сланцевой смоле туннельных печей $\left(192-290^{\circ}\right)$, а также индивидуальные ароматические углеводороды, образовавшиеся при дегидроксилировании указанных фенолов, и их содержание. Как видно, 0 -крезола и 0 -этилфенола значительно меньше, чем $\boldsymbol{\mu}$ - и $n$-изомеров. В высокотемпературной области распределение не вполне отчетливо. В незначительном количестве встречается 2,6-структура среди фенолов с двумя алкильными группами. По сравнению с фенолами камерных печей [7] $\boldsymbol{н}$-пропилфенола больше, а этилфенола меньше. Это объясняется, очевидно, более сильной деструкцией в камерных печах. Сравнение идентифицированных групп фенолов с фенолами камерной печи и каменного угля приведено в табл. 4.

Исследованные фенолы туннельной печи содержат относительно меньше легких компонентов - фенолов и крезолов, чем фенолы камерной печи и каменного угля, но больше алкилфенолов. Такая разница в составе групп фенолов обусловлена различной температурой в уста. Таблица 4

Сравнительные данные выхода сланцевых (туннельных и камерных) и каменноугольных фенолов

\begin{tabular}{|c|c|c|c|}
\hline \multirow[b]{2}{*}{ Показатели } & \multicolumn{3}{|c|}{ Фенолы } \\
\hline & $\begin{array}{c}\text { туннель- } \\
\text { ные } \\
\text { сланце- } \\
\text { вые * }\end{array}$ & $\mid \begin{array}{c}\text { камерные } \\
\text { сланце- } \\
\text { вые [] ** }\end{array}$ & $\begin{array}{c}\text { каменно- } \\
\text { угольные } \\
{[10]}\end{array}$ \\
\hline Содержание фенолов & & & \\
\hline $\begin{array}{l}\text { в смоле, вес. \% } \\
\text { Выход фенолов в пе- } \\
\text { ресчете на исход- }\end{array}$ & 3,8 & 2,8 & $1,8-2,1$ \\
\hline $\begin{array}{l}\text { ное твердое топли- } \\
\text { во, вес. \% }\end{array}$ & 0,15 & 0,14 & $0,06-0,08$ \\
\hline $\begin{array}{l}\text { Содержание компо- } \\
\text { нентов в фенолах, } \\
\text { вес. \%: }\end{array}$ & & & \\
\hline $\begin{array}{l}\text { фенол } \\
\text { крезолы }\end{array}$ & $\begin{array}{r}3,7 \\
13,5\end{array}$ & $\begin{array}{r}8,1 \\
25,6\end{array}$ & $\begin{array}{l}12-18 \\
30-39\end{array}$ \\
\hline $\begin{array}{l}\text { ксиленолы и этил- } \\
\text { фенолы }\end{array}$ & 19,5 & 20,1 & $15-17$ \\
\hline $\begin{array}{l}\text { алкилфенолы } \\
\text { нафтолы }\end{array}$ & 22,9 & $\begin{array}{l}15,9 \\
15,6\end{array}$ & $3-5$ \\
\hline нафтолы & 10,0 & 15,0 & \\
\hline
\end{tabular}

* Фенолы, кипящне до $290^{\circ}$.

** Фенолы, кипящие до $300^{\circ}$. новках полукоксования.

В индивидуальном составе различие меньше. Так же, как в фенолах камерных печей, здесь в большем количестве представлены инданолы. Отличительная черта - присутствие фенолов типа тетралина. Структура фенолов в основном такая же, как у ароматических углеводородов сланцевой смолы [1']. Так как исходное масло содержит ароматические углеводороды типа тетралина, то присутствие фенолов такой структуры вполне естественно.

Из общего количества смеси фенолов, взятого в опыт, было идентифицировано около $80 \%$ фенолов и около $88 \%$ ароматических структур. Неидентифицированные соединения принадлежат к пределу температур кипения $250-280^{\circ}$. 


\section{ЛИТЕРАТУ РА}

1. Р аудсепп Х. Т., Исследованне фенолов сланцевой смолы. Днссертация,

2. Кестнер А. И., Тр. Таллннск. политехн. ин-та, Серия А, № 198, 57 (1962).

3. Kusý V., Gaschromatographie 1961, 3. Symp. G.-Chrom., Berlin, 1962.

4. J a n a k J., Komers R., Sim a J., Collect. Czechosl. Chem. Communs, 24, No. 5 , 1492 (1959).

5. К лесм ент И., Эй зен О., Изв. АН ЭССР. Сер. физ.-матем. и техн. наук, № 1 , 147 (1965).

6. Клесмент И. Р., Р анг С. А., Эй зен О. Г., Нефтехимия, 3, № 6, 864 (1963).

7. Э й з ен О. Г., К л ес мен т И. Р., Бюлл. науч.-техн. информации «Горючне сланцы», № 5, 30 (1963).

8. Fitz ge r a ld J. S., Australian J. Appl. Sci., 10, No. 2, 169 (1959).

9. Эйзен Ю., Киррет О., Эйзен О., Изв. АН ЭССР. Сер. физ.-матем. и. техн. наук, № 1, 22 (1964).

10. Лнплавк И. Л., Физико-хнмическне свойства химических продуктов полукоксовання каменных углей, Металлургиздат, 1954.

11. Эй зен О., Эй зе н Ю., Изв. АН ЭССР. Сер. физ.-матем. и техн. наук, № 4, 424-433 (1963).

12. Handbook of Chemistry and Physics, Ed. 37, Chemical Rubber Publishing Co, Cleveland, Ohio, 1955-1956.

\section{Ннститут химии \\ Академии наук Эстонской ССР}

Поступила в редакцию 19/IX 1964

\section{S. SALUSTE, I. KLESMENT, O. EISEN}

\section{TUNNELAHJU-FENOOLIDE KEEMILINE KOOSTIS}

Uuriti tunnelahju-fenoolide fraktsiooni $192-290^{\circ} \mathrm{C}$ keemilist koostist. Kasutati kahteparalleelset analüüsimeetodit: 1) otsest gaasikromatograafiat, 2) fenoolide dehüdroksüleerimist aromaatseiks süsivesinikeks mikroreaktorgaasikromatograafilises seadmes.

Leiti rohkesti etüül- ja propüülrühmaga fenoole, indanoole ja tetraliinitüüpi fenoole:

\section{S. S.ALUSTE, I. KLESMENT, O. EISEN}

\section{THE CHEMICAL COMPOSITION OF PHENOLS OF SHALE OIL}

The chemical composition of the phenol fraction $192-290^{\circ} \mathrm{C}$ of shale oil was investigated. Two parallel methods of analysis were applied: 1) direct gas-liquid chromatography, 2) dehydroxylation of phenols to aromatic hydrocarbons in a microreactorgaschromatographic apparatus.

It was found that the fraction contains a considerable number of phenolic compounds with ethylic and propylic groups, indanols and phenolic compounds of tetraline type. 